\title{
Adsorption Thermodynamics and Dynamics of Three Typical Dyes onto Bio-adsorbent Spent Substrate of Pleurotus eryngii
}

\author{
Jianguo Wu ${ }^{1,2, *}$, Aiqiang Xia ${ }^{1}$, Chunyan Chen ${ }^{1}$, Liuying Feng ${ }^{1}$, Xiaohui Su ${ }^{1}$ and \\ Xinfeng Wang ${ }^{1,2}$ \\ 1 Jiangsu Key Laboratory for Eco-Agricultural Biotechnology around Hongze Lake, Jiangsu Key Construction \\ Laboratory for Food Safe and Nutritional Function, School of Life Science, Huaiyin Normal University, \\ Changjiang West Road 111, Huai'an 223300, China; aiqingxia163@163.com (A.X.); \\ chunyanchen0905@163.com (C.C.); 18360908332@163.com (L.F.); 15751333929@163.com (X.S.); \\ wangxf@hytc.edu.cn (X.W.) \\ 2 Jiangsu Collaborative Innovation Center of Regional Modern Agriculture and Environmental Protection, \\ Huaiyin Normal University, Changjiang West Road 111, Huai'an 223300, China \\ * Correspondence: jgwu_21@sina.cn; Tel.: +86-517-83525992
}

Received: 8 January 2019; Accepted: 21 February 2019; Published: 26 February 2019

\begin{abstract}
Dyeing wastewater is very hard to treat, and adsorption could be a good choice. Spent substrate of Pleurotus eryngii (SSPE) was first used to adsorb malachite green, safranine $\mathrm{T}$ and methylene blue from aqueous solutions, and the corresponding adsorption isotherm, thermodynamics and dynamics models were simulated. More than $93 \%$ of the dyes were removed with solutions with $100 \mathrm{mg} / \mathrm{L}$ of initial dye concentration, $1 \mathrm{~g}$ of SSPE and $\mathrm{pH}$ of 6.0 after adsorption for $4 \mathrm{~h}$. Freundlich isotherm models fit better the adsorption data than Langmuir models. Adsorption of the dyes onto SSPE was a spontaneous exothermic process based on an adsorption thermodynamics model. SSPE could adsorb the dyes rapidly, and a second-order kinetics model fit better with the adsorption data than a pseudo first-order kinetics model. Accordingly, SSPE could be a good bio-adsorbent for the removal of malachite green, safranine $\mathrm{T}$ and methylene blue from the aqueous solution.
\end{abstract}

Keywords: bio-adsorption; thermodynamics; isotherms; kinetics; spent mushroom substrate

\section{Introduction}

Dyeing wastewater is discharged from cotton, linen, chemical fibers and their blended products, silk-based printing and dyeing, wool dyeing and finishing and silk factories. Dyeing wastewater is very hard to treat because of its large amount of water, high content of organic pollutants, high alkalinity and great change of water quality, which results in dyeing wastewater pollution [1]. Even more serious, many dyes threaten human health seriously because of their toxic, carcinogenic and mutagenic effects [2-5]. Dyes in the dyeing wastewater could be reused by adsorption and desorption [6]. In recent years, some new synthetic adsorbents and bio-adsorbents originated from agriculture and food industry waste for the removal of dyes wastewater was found and have attracted a lot of attention, such as Amberlite IRA-938 resin [7], starch/poly(alginic acid-cl-acrylamide) nanohydrogel [8], orange peel, sawdust, rice husk and spent substrate of Ganodorma lucidum [9-12]. Basic dyes are one of the major categories of dyes, and are suitable for dyeing of acrylic fibers, terylene, nylon, cellulose and protein fiber. Typical basic dyes include the triarylmethane dye malachite green, the azine dye safranine $\mathrm{T}$ and the thiazine dye methylene blue. Their chemical structures were shown in Figure 1. 
<smiles>CN(C)c1ccc(C(=C2C=CC(=[N+](C)C)C=C2)c2ccccc2)cc1</smiles>

malachite green<smiles>Cc1cc2nc3cc(C)c(N)cc3[n+](-c3ccccc3)c2cc1N</smiles>

safranine T<smiles>C[N+]=c1ccc2nc3ccc(N(C)C)cc3sc-2c1</smiles>

methylene blue

Figure 1. The chemical structures of malachite green, safranine $\mathrm{T}$ and methylene blue.

In 2011, the mushroom yield in China was over 20 million tons, which was seventy five percent of the world output [13]. The turnout of spent mushroom substrate (SMS) was more than 8 million tons. SMS had thus become one of the major agriculture wastes. Except for a few examples of SMS being used for returning to the field [14], feedstuffs [15], cultivation [16], fuel and energy materials [17], the vast majority of SMS was abandoned and caused environmental pollution. Because of the abundant surface hydroxyl, carbonyl, and carboxyl groups in SMS [12], SMS could be considered as a potentially useful low-cost bio-adsorbent for dyeing wastewater treatment. However, there was only a few studies using SMS as bio-adsorbent to adsorb dyes and heavy metals [18-20].

Pleurotus eryngii has been widely cultivated all over the world, and its automated batch production has been realized. However, the utilization of spent substrate of P. eryngii (SSPE) is still a difficult problem [21]. In this study, SSPE was used for the first time as a bio-adsorbent for the adsorption of three typical dyes: the triarylmethane dye malachite green, the azine dye safranine $T$ and the thiazine dye methylene blue from aqueous solutions, and the corresponding adsorption isotherm, thermodynamics and dynamics models were also simulated.

\section{Materials and Methods}

\subsection{Preparation of Bio-Adsorbent}

SSPE was obtained from an edible fungus factory located in Huai'an, China, and washed with tap water first, then distilled water. The SSPE was milled and sieved after it was dried at $60^{\circ} \mathrm{C}$ for $72 \mathrm{~h}$. The particles $\leq 0.25 \mathrm{~mm}$ was picked for use as bio-adsorbent.

\subsection{Preparation of Dye Solution}

Three stock solutions of $200 \mathrm{mg} / \mathrm{L}$ were prepared by dissolving $100.0 \mathrm{mg}$ of malachite green (Shenyang Chascitek Chemical Co., Ltd, Shenyang, China), safranine T (Shanghai Fortunei Bio-tech Co., Ltd, Shanghai, China) or methylene blue (Shanghai Yuanye Bio-tech Co., Ltd, Shanghai, China) in $500 \mathrm{~mL}$ of double-distilled water. All the chemicals were analytical-grade reagents. The initial $\mathrm{pH}$ was adjusted with $0.1 \mathrm{~mol} / \mathrm{L} \mathrm{HCl}$ or $0.1 \mathrm{~mol} / \mathrm{L} \mathrm{NaOH}$.

\subsection{Batch Bio-Adsorption Procedure}

Our batch bio-adsorption procedures included an experimental group and a control group. The batch bio-adsorption of experimental group was conducted in $250 \mathrm{~mL}$ conical flasks with $100 \mathrm{~mL}$ solution of malachite green, safranine $\mathrm{T}$ or methylene blue $(10,20,50,80,100$ and $120 \mathrm{mg} / \mathrm{L}$ of concentration) mixed individually with $1 \mathrm{~g}$ of SSPE under different conditions of $\mathrm{pH}(2.0,4.0,6.0,8.0$, 10.0 and 12.0) and absolute temperature $(288,293,298,303,308,313,318,328$, and $338 \mathrm{~K})$ for different times $(1,3,5,7,10,20$, and $30 \mathrm{~min})$ or with $4 \mathrm{~h}$ equilibrium time. All the adsorption experiments were carried out in the shaker controlled by a thermostat (uncertainty of $\pm 0.5 \mathrm{~K}$ ). Control group experiments were also conducted under the same batch bio-adsorption procedure conditions of the experimental groups but without SSPE. 


\subsection{Determination of Concentration of Dyes}

The equilibrium suspensions were centrifuged at a speed $(7000 \mathrm{r} / \mathrm{min})$ for $10 \mathrm{~min}$, and the concentrations of dyes were determined by a UV-vis spectrophotometric method using a UV-vis spectrophotometer (754, Shanghai Sunny Hengping Instrument Co., Ltd., Shanghai, China) with glass cells of path length $1 \mathrm{~cm}$ at wavelength $\lambda_{\text {malachite green }} 617 \mathrm{~nm}, \lambda_{\text {safranine T }} 530 \mathrm{~nm}$ and $\lambda_{\text {methylene blue }}$ $664 \mathrm{~nm}$. All data were measured five times.

\subsection{Removal Efficiency by Adsorption and Equilibrium Adsorption Quantity}

Removal efficiency by adsorption (R) of dye onto SSPE was calculated by Equation (1), and the equilibrium adsorption quantity of SSPE for dye, Qe $(\mathrm{mg} / \mathrm{g})$, was calculated by Equation (2).

$$
\begin{aligned}
& R=\frac{C_{0}-C e}{C_{0}} \times 100 \% \\
& Q e=\left(C_{0}-C e\right) \times \frac{V}{W}
\end{aligned}
$$

where $C_{0}$ and $C e$ are the equilibrium liquid-phase concentrations of the dyes of the control group and experimental group, respectively $(\mathrm{mg} / \mathrm{L}), V$ is the volume of the experimental solution $(=0.1 \mathrm{~L})$, and $W$ is the weight of the SSPE used $(=1 \mathrm{~g})$.

\subsection{Assays by Fourier Transform Infrared Spectroscopy (FTIR)}

$\mathrm{KBr}$ pellets were prepared with $2 \mathrm{mg}$ SSPE in $40 \mathrm{mg} \mathrm{KBr}$ for FTIR spectroscopy using a Nicolet iS50 spectrometer (Thermo Scientific, Waltham, MA, USA). Spectral measurement ranged from 400 to $4000 \mathrm{~cm}^{-1}$ with $0.4 \mathrm{~cm}^{-1}$ resolution.

\subsection{Adsorption Thermodynamics and Dynamics Model}

\subsubsection{Adsorption Isotherm Model}

To evaluate the adsorption isotherm of dyes onto adsorbent, the Langmuir and Freundlich models are widely used [22]. The Langmuir model is suitable for single molecule adsorption, and can be expressed linearly by Equation (3) as follows:

$$
\frac{C e}{Q e}=\frac{C e}{Q m}+\frac{1}{K_{L} \times Q m}
$$

The Freundlich model provides an empirical description of the single component adsorption equilibrium, and is applicable within a broader scope. The Freundlich model can be expressed as Equation (4):

$$
\ln Q e=\ln K_{F}+\frac{1}{n} \ln C e
$$

where $\mathrm{Ce}$ is the equilibrium liquid-phase concentrations of the dye $(\mathrm{mg} / \mathrm{L}), \mathrm{Qe}$ and $\mathrm{Qm}$ are the equilibrium and maximum adsorbed amount of dye per mass of SSPE, respectively $(\mathrm{mg} / \mathrm{g}), K_{L}$ is the Langmuir equilibrium adsorption constant $(\mathrm{L} / \mathrm{mg})$ related to the free energy of adsorption, $K_{F}$ is the Freundlich constant $\left[(\mathrm{mg} / \mathrm{g})(\mathrm{L} / \mathrm{mg})^{1 / n}\right]$ related to the strength of the adsorptive bond, and $1 / n$ is the adsorption intensity factor or surface heterogeneity.

\subsubsection{Adsorption Thermodynamics}

To evaluate the adsorption thermodynamics of dyes onto the adsorbent, Equation (5) is widely used [12]: 


$$
\ln \frac{C_{B e}}{C_{A e}}=-\frac{\Delta H}{R T}+\frac{\Delta S}{R}
$$

where $C_{B e}$ and $C_{A e}$ represent the equilibrium concentrations of the dye in adsorbent and solution $(\mathrm{mg} / \mathrm{L}), \Delta H$ is adsorption enthalpy change $\left(\mathrm{kJ} \mathrm{mol}^{-1}\right), \Delta S$ is adsorption entropy change $\left(\mathrm{J} \mathrm{mol}^{-1} \mathrm{~K}^{-1}\right)$, $R$ is the molar gas constant $\left(8.314 \mathrm{~J} \mathrm{~mol}^{-1} \mathrm{~K}^{-1}\right)$, and $T$ is the absolute temperature $(\mathrm{K})$.

\subsubsection{Adsorption Kinetics}

To evaluate the adsorption kinetics, the pseudo first-order (Equation (6)) and second-order kinetics (Equation (7)) shown below are used widely [23]:

$$
\begin{gathered}
\ln (Q e-Q t)=\ln Q e-k_{1} t \\
\frac{t}{Q t}=\frac{t}{Q e}+\frac{1}{k_{2} Q e^{2}}
\end{gathered}
$$

where $Q e$ and $Q t$ represent the adsorption capacities $(\mathrm{mg} / \mathrm{g})$ of SSPE at equilibrium and at a particular time $t(\mathrm{~min})$, respectively. The first-order and second-order kinetic rate constants are denoted by $k_{1}$ $(1 / \mathrm{min})$ and $k_{2}[(\mathrm{~g} / \mathrm{mg})(1 / \mathrm{min})]$.

\section{Results}

\subsection{Effect of $\mathrm{pH}$ on Dyes Adsorption}

The effect of $\mathrm{pH}$ on the removal of malachite green, safranine $\mathrm{T}$ and methylene blue from the solutions is shown in Figure 2.

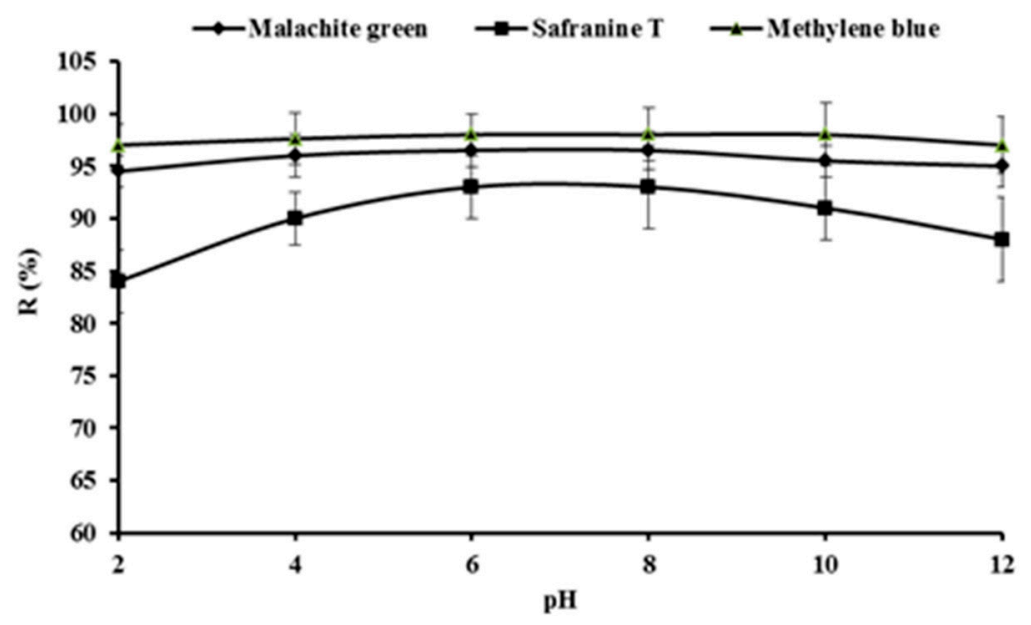

Figure 2. Adsorption removal efficiency of malachite green, safranine $\mathrm{T}$ and methylene blue onto SSPE under different $\mathrm{pH}$ in solutions at $100 \mathrm{mg} / \mathrm{L}$ of initial dyes concentration, $1 \mathrm{~g}$ of SSPE and $303 \mathrm{~K}$ of temperature for $4 \mathrm{~h}$.

When the initial $\mathrm{pH}$ of the dyes solutions was increased from 2 to 12, the adsorption removal efficiency of malachite green and methylene blue onto SSPE remained stable at about $95 \%$, so $\mathrm{pH}$ had little effect on the adsorption of malachite green and methylene blue. As the $\mathrm{pH}$ increased from 2 to 6 , the adsorption removal efficiency of safranine T onto SSPE increased from 84 to $93 \%$. By further increasing the $\mathrm{pH}$ to 8 , the adsorption removal efficiency changed little, while with an increase of the $\mathrm{pH}$ from 8 to 12, the adsorption removal efficiency of safranine T decreased from 93 to $88 \%$. Therefore, $\mathrm{pH}$ affected the adsorption of safranine T onto SSPE, and around neutral $\mathrm{pH}(6-8)$ was propitious for safranine $\mathrm{T}$ to be adsorbed onto the SSPE in solution. Safranine $\mathrm{T}\left(\mathrm{SH}^{+}\right)$undergoes triplet excited state proton-transfer reactions, and $\mathrm{SH}^{+}$reacted with protons or hydroxy ions to form the dication $\mathrm{SH}_{2}{ }^{2+}$ 
or the neutral ${ }^{3} \mathrm{~S}$ species. SSPE could have different adsorption capacity for safranine $\mathrm{T}$ in different states [24], which lead to the effect of $\mathrm{pH}$ on the removal of safranine T by SSPE.

SSPE is rich in functionalg groups such as -OH $\left(3420 \mathrm{~cm}^{-1}\right)$ and -COOH $\left(1650 \mathrm{~cm}^{-1}\right)$ according to the FTIR spectruma shown in Figure 3, which means that the SSPE surface is rich in anions. Malachite green, safranine $\mathrm{T}$ and methylene blue are all basic dyes, which are in a cationic state in water, so the dyes could be adsorbed onto SSPE by electrostatic attractions. SSPE was also used to adsorb acid the dye amaranth in this study, but it was found it was very hard to adsorb amaranth on SSPE. Consequently, SSPE should be a good bio-adsorbent for the basic dyes malachite green, safranine T and methylene blue, with adsorption removal efficiencies of more than $93 \%$. The dyes on SSPE could be further recycled by extraction technology, and the adsorbent could be reused further by bio-pretreatment with white-rot fungi [12].

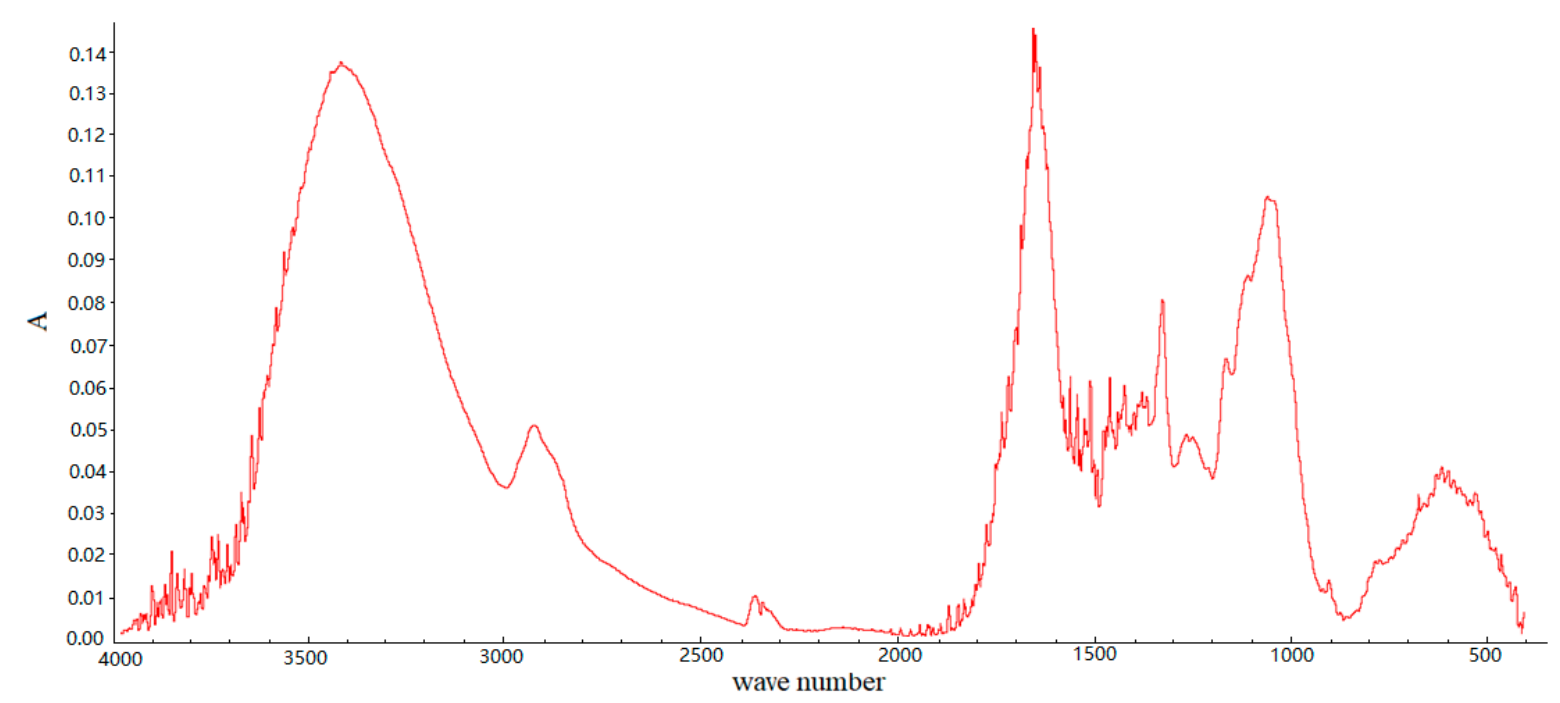

Figure 3. The FTIR spectrum of SSPE.

\subsection{Adsorption Isotherm}

The adsorption removal efficiency of malachite green, safranine $\mathrm{T}$ and methylene blue onto SSPE generally decreased with the increase of initial dye concentration from $10 \mathrm{mg} / \mathrm{L}$ to $120 \mathrm{mg} / \mathrm{L}$, as shown in Figure 4a.

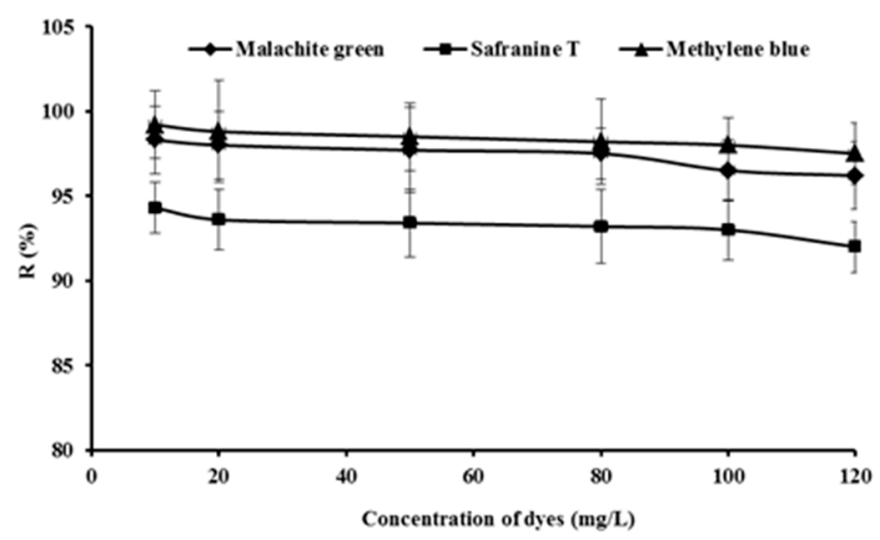

(a)

Figure 4. Cont. 


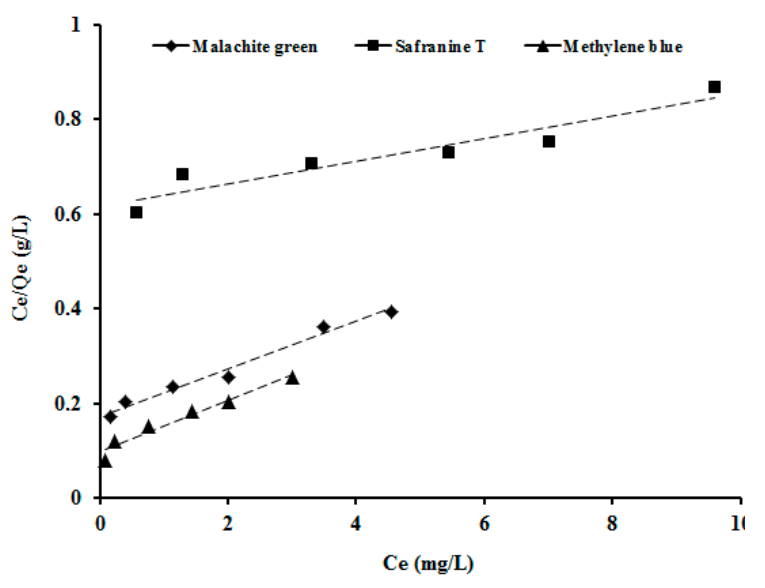

(b)

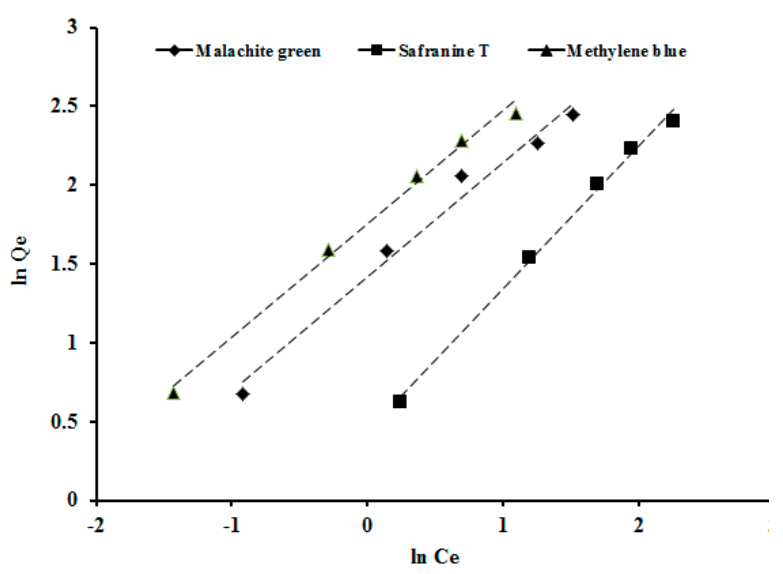

(c)

Figure 4. Adsorption removal efficiency of malachite green, safranine $\mathrm{T}$ and methylene blue onto $1 \mathrm{~g}$ of SSPE with different initial dye concentrations, at $\mathrm{pH} 6.0$ and $303 \mathrm{~K}$ of temperature for $4 \mathrm{~h}$ (a), plots of Langmuir (b) and Freundlich (c) isotherms. The solid lines are the experimental data, and the dashed lines are the linearized Langmuir and Freundlich fitted models.

To effectively evaluate the Langmuir isotherm, the values of $C e / Q e$ were plotted vs $C e$ as shown in Figure $4 \mathrm{~b}$, and the values of $K_{L}$ and $Q m$ were obtained as shown in Table 1 by the slope and intercept of the best fit line, respectively. Furthermore, the Freundlich isotherm parameters of $1 / n$ and $K_{F}$ were obtained by plotting the values of $\ln Q e$ vs $\ln C e$ as shown in Figure $4 \mathrm{c}$ and Table 2. The regression coefficient $\left(R^{2}\right)$ was used to evaluate the fit effect of the Langmuir and Freundlich isotherms to the experimental data. $Q m$ of safranine $\mathrm{T}$ was higher than that of malachite green and methylene blue. However, the $R^{2}$ of safranine T was below 0.9 , which meant that adsorption isotherm parameters of safranine T onto SSPE had low feasibility according to the Langmuir model. $K_{F}$ is related to the strength of the adsorptive bond. The value of $K_{F}$ of safranine $T$ was lower than that of other dyes, which meant that SSPE had a weak adsorptive bond strength for safranine T. The value of $K_{F}$ of methylene blue was the highest, which meant that methylene blue was most effectively removed by SSPE. That result was also consistent with the adsorption data. However, the values of $K_{F}$ of malachite green, safranine T or methylene blue onto SSPE were all lower than that onto synthetic adsorbents, such as Jalshakti ${ }^{\circledR}$ (Indian Organic Chemicals Ltd., Khopoli, Raigad, India) [25] or $\mathrm{Fe}_{3} \mathrm{O}_{4} @$ AMCA-MIL-53(Al) nanocomposite synthesized by Alqadami etal [26]. As bio-adsorbent, the values of $K_{F}$ of methylene blue onto SSPE was lower than those of activated lignin-chitosan extruded blends [27] but higher than brown macroalgae [28]. Based on the alignment of the experimental data with the model lines in Figure $4 b, c$, together with the regression coefficient $\left(R^{2}\right)$ in Tables 1 and 2, it was clear that Freundlich model fitted the adsorption data better than the Langmuir model, which means that the adsorption of dyes took place on the monolayer surface of SSPE and the dye and SSPE interacted with each other during the adsorption process. Values of " $n$ " obtained from the Freundlich isotherm were all above 1 , which indicates potential good adsorption of the dyes onto SSPE.

Table 1. Langmuir model coefficients.

\begin{tabular}{cccc}
\hline Dye & $Q m(\mathbf{m g} / \mathbf{g})$ & $K_{L}(\mathrm{~L} / \mathbf{m g})$ & $R^{2}$ \\
\hline Malachite green & 19.23 & 0.3071 & 0.986 \\
Safranine T & 42.02 & 0.0386 & 0.897 \\
Methylene blue & 18.45 & 0.5503 & 0.957 \\
\hline
\end{tabular}


Table 2. Freundlich model coefficients.

\begin{tabular}{|c|c|c|c|c|c|c|c|}
\hline Dye & $n$ & $\begin{array}{c}K_{F} \\
(\mathrm{mg} / \mathrm{g})(\mathrm{L} / \mathrm{mg})^{1 / \mathrm{n}}\end{array}$ & $R^{2}$ & $n^{*}$ & $\begin{array}{c}K_{F}^{*} \\
(\mathrm{mg} / \mathrm{g})(\mathrm{L} / \mathrm{mg})^{1 / \mathrm{n}}\end{array}$ & $R^{2 *}$ & Ref. \\
\hline \multirow{2}{*}{ Malachite green } & \multirow{2}{*}{1.38} & \multirow{2}{*}{4.12} & \multirow{2}{*}{0.981} & 1.58 & 8.30 & 0.980 & [25] \\
\hline & & & & 2.18 & 26.27 & 0.980 & [26] \\
\hline \multirow{2}{*}{ Safranine $\mathrm{T}$} & \multirow{2}{*}{1.11} & \multirow[t]{2}{*}{1.55} & \multirow[t]{2}{*}{0.995} & 1.28 & 15.50 & 0.990 & [25] \\
\hline & & & & 2.08 & 58.90 & 0.980 & [25] \\
\hline \multirow{3}{*}{ Methylene blue } & \multirow{3}{*}{1.39} & \multirow{3}{*}{5.77} & \multirow{3}{*}{0.993} & 2.04 & 19.31 & 0.983 & [26] \\
\hline & & & & 2.47 & 7.02 & 0.978 & [27] \\
\hline & & & & 1.05 & 1.13 & 0.999 & [28] \\
\hline
\end{tabular}

${ }^{*}$ Results from related references.

\subsection{Adsorption Thermodynamics}

Adsorption removal efficiency of malachite green, safranine $\mathrm{T}$ and methylene blue onto SSPE decreased with increase of adsorption temperature as shown in Figure 5a, which indicates that a higher temperature was unfavourable to the adsorption of the dyes onto SSPE.

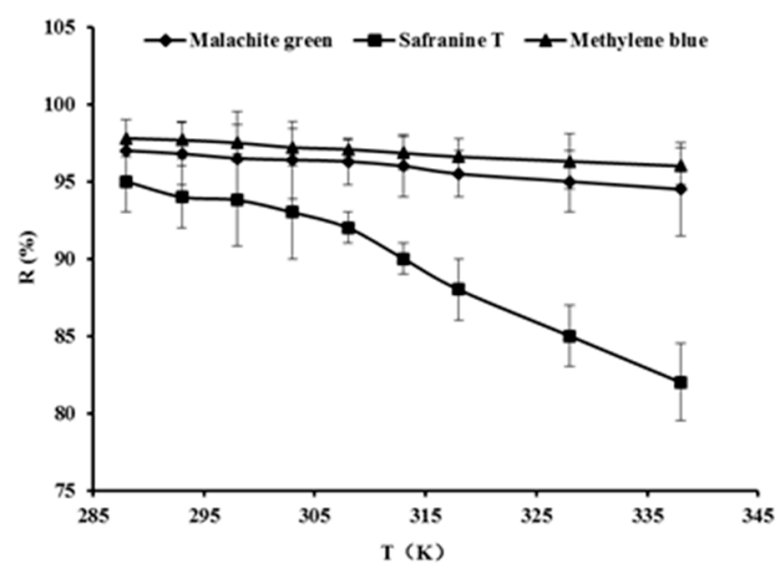

(a)

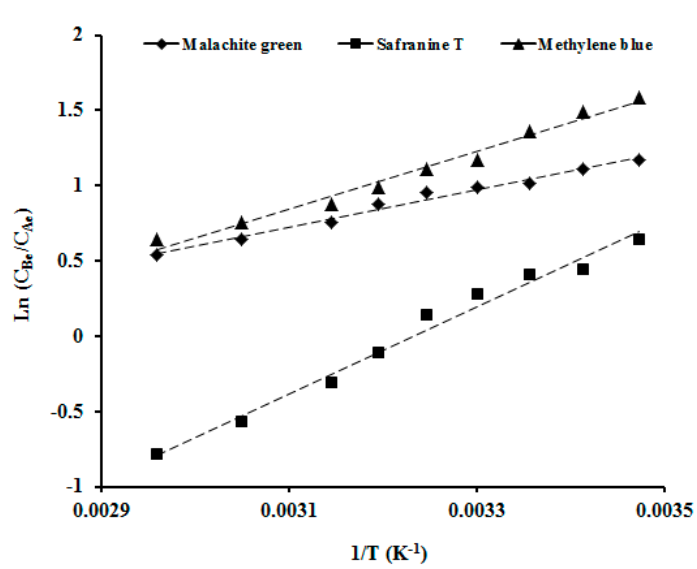

(b)

Figure 5. Adsorption removal efficiency of malachite green, safranine T and methylene blue onto SSPE with different temperature at $100 \mathrm{mg} / \mathrm{L}$ of initial dyes concentration, $1 \mathrm{~g}$ of SSFV and $6.0 \mathrm{of} \mathrm{pH}$ for $4 \mathrm{~h}$ (a), and plots of adsorption thermodynamics (b). The solid lines were experimental data, and dashed lines were the linearized adsorption thermodynamics fitted model.

The adsorption thermodynamics model was established by plotting the value of $\ln \left(C_{B e} / C_{A} e\right)$ against the reciprocal of the temperature $(1 / T)$ to calculate the values of $\Delta H$ and $\Delta S$ and the regression coefficients $\left(R^{2}\right)$ as shown in Figure $5 \mathrm{~b}$ and Table 3. $R^{2}$ of the adsorption thermodynamics model of the dyes onto SSPE were all greater than 0.98 , which indicated that the model fit well with the data of the dyes adsorption onto SSPE. $\Delta H$ and $\Delta S$ were all negative. Negative enthalpy indicates that the adsorption of dyes onto SSPE was an exothermic process. Negative entropy means that the degree of system chaos decreased because the dissolved dyes were adsorbed onto SSPE.

Table 3. Coefficients of adsorption thermodynamics.

\begin{tabular}{cccc}
\hline Dye & $\left.\boldsymbol{\Delta} \boldsymbol{H} \mathbf{( \mathbf { k J ~ m o l }} \mathbf{~ m}^{-1}\right)$ & $\boldsymbol{\Delta S} \mathbf{( \mathbf { J ~ m o l } ^ { - 1 } \mathbf { K } ^ { - 1 } )}$ & $\boldsymbol{R}^{\mathbf{2}}$ \\
\hline Malachite green & -10.35 & -26.1 & 0.984 \\
Safranine T & -23.99 & -77.5 & 0.983 \\
Methylene blue & -16.00 & -42.6 & 0.981 \\
\hline
\end{tabular}


Gibbs free energy $(\Delta G)$ was used as a criterion for spontaneity and equilibrium of constant temperature and pressure processes, and was defined as Equation (8) [29]:

$$
\Delta G=\Delta \mathrm{H}-\Delta S \times T
$$

The $\Delta G$ of malachite green and methylene blue adsorbing onto SSPE were all negative, which indicated that the adsorption process was a spontaneous process [30]. $\Delta G$ of safranine $T$ adsorbing onto SSPE at the temperature ranged from 288 to $308 \mathrm{~K}$ was negative also, but the $\Delta G$ was positive when the adsorption temperature was above $308 \mathrm{~K}$, so the adsorption process of safranine $\mathrm{T}$ onto SSPE was a spontaneous process below $308 \mathrm{~K}$, and a non-spontaneous process above $308 \mathrm{~K}$.

\subsection{Adsorption Kinetics}

The adsorption removal efficiency of the three dyes malachite green, safranine $\mathrm{T}$ and methylene blue onto SSPE increased with the increase of adsorption time as shown in Figure 6a. The adsorption removal efficiency of the three dyes all exceeded $86 \%$ during the initial three minutes, and then increased slowly during the subsequent adsorption time. Therefore, SSPE could efficiently adsorb malachite green, safranine $\mathrm{T}$ and methylene blue.

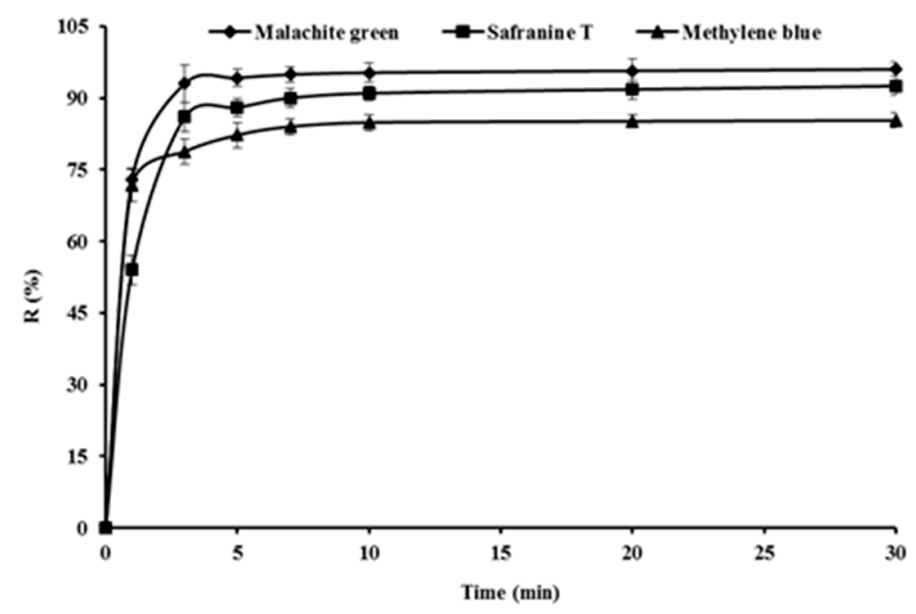

(a)

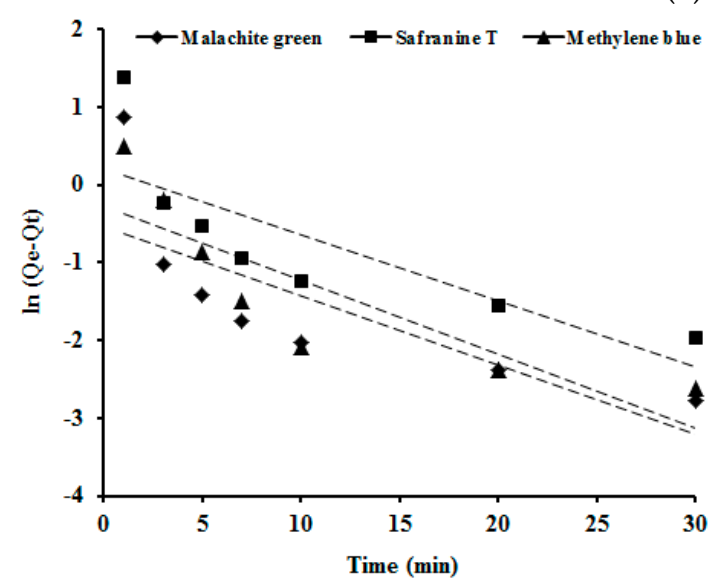

(b)

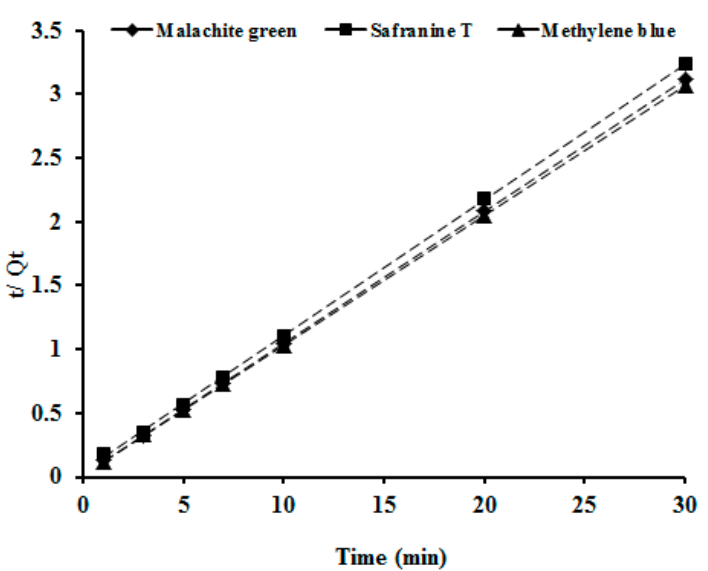

(c)

Figure 6. Adsorption removal efficiency of malachite green, safranine T and methylene blue by SSPE 1 $\mathrm{g}$ of SSFE with different times at $100 \mathrm{mg} / \mathrm{L}$ of initial dye concentration, $\mathrm{pH} 6.0$ and $303 \mathrm{~K}$ of temperature. (a), Plots of first-order kinetics (b) and second-order kinetics (c). The solid lines are the experimental data, and the dashed lines are the linearized first-order and second-order kinetics fitted models. 
The pseudo first order kinetic model was established by plotting the value of $\ln (Q e-Q t)$ vs time $(t)$ to calculate the values of $k_{1}$ and $R^{2}$ as shown in Figure $6 \mathrm{~b}$ and Table 4. Moreover, the values of $k_{2}, Q e$, and $R^{2}$ of the pseudo second order kinetic model were obtained by plotting the values of $t / Q t$ vs time $(t)$ as shown in Figure $6 \mathrm{c}$ and Table $4 . R^{2}$ values of the two kinetic models were compared to obtain which model fitted better with the dye adsorption onto SSPE data. The linear plot of $\mathrm{t} / \mathrm{Q} t \mathrm{vs} t$ as shown in Figure $6 \mathrm{c}$ indicates the applicability of the second-order kinetic model and good agreement with the obtained experimental data. The adsorption capacities of malachite green, safranine $\mathrm{T}$ and methylene blue onto SSPE at equilibrium $(Q e)$ were $9.662,9.389$ and $9.823 \mathrm{mg} / \mathrm{g}$, respectively. The $R^{2}$ of the second-order kinetic model was much better than that of the first order kinetic model, which indicated that second-order kinetic model was suitable to describe the adsorption kinetics of the dyes.

Table 4. Coefficients of the first and second order kinetic models.

\begin{tabular}{cccccc}
\hline \multirow{2}{*}{ Dye } & \multicolumn{2}{c}{ First Order Kinetic Model } & \multicolumn{3}{c}{ Second Order Kinetic Model } \\
\cline { 2 - 6 } & $\boldsymbol{k}_{\mathbf{1}} \mathbf{( 1 / \mathbf { m i n } )}$ & $\boldsymbol{R}^{\mathbf{2}}$ & $\mathbf{Q e}(\mathbf{m g} / \mathbf{g})$ & $\boldsymbol{k}_{\mathbf{2}}(\mathbf{g} / \mathbf{m g}) \cdot(\mathbf{1} / \mathbf{m i n})$ & $\boldsymbol{R}^{\mathbf{2}}$ \\
\hline Malachite green & 0.0891 & 0.609 & 9.662 & 0.595 & $\approx 1$ \\
Safranine T & 0.0849 & 0.652 & 9.389 & 0.259 & $\approx 1$ \\
Methylene blue & 0.0948 & 0.725 & 9.823 & 0.503 & $\approx 1$ \\
\hline
\end{tabular}

In a word, the results obtained in this study suggest that SSPE has the potential to be an economic and efficient bio-adsorbent for malachite green, safranine $\mathrm{T}$ and methylene blue removal from water and wastewater resources. A filtration unit incorporating SSPE as bio-adsorbent could be operated based on the conditions, adsorption thermodynamics and dynamics model obtained in this study in a full-scale water and wastewater treatment plant for the removal of malachite green, safranine $\mathrm{T}$ and methylene blue from contaminated waters.

\section{Conclusions}

SSPE should be a good bio-adsorbent for the basic dyes malachite green, safranine $\mathrm{T}$ and methylene blue, as the adsorption removal efficiencies were more than $93 \%$. Freundlich isotherm models fit better with the adsorption data than Langmuir models. Adsorption of the dyes onto SSPE was a spontaneous exothermic process based on adsorption thermodynamics model. SSPE could adsorb the three dyes rapidly, and kinetic analysis of the dyes adsorption onto SSPE showed a good alignment with the second-order kinetics model.

Author Contributions: Writing-Original Draft Preparation, Writing-Review \& Editing and Funding Acquisition, J.W.; Data Curation and Formal Analysis, A.X.; Data Curation, C.C.; Methodology, L.F.; Investigation, X.S.; Project Administration, X.W.

Funding: This work was supported by the National Natural Science Foundation of China (grant number 31870543); and the Jiangsu Collaborative Innovation Center of Regional Modern Agriculture \& Environmental Protection (grant number HSXT2-310).

Acknowledgments: This work was supported by the National Natural Science Foundation of China and the Jiangsu Collaborative Innovation Center of Regional Modern Agriculture \& Environmental Protection.

Conflicts of Interest: The authors declare no conflict of interest.

\section{References}

1. Dos Santos, R.F.; Ramlow, H.; Dolzan, N.; Machado, R.A.F.; de Aguiar, C.R.L.; Marangoni, C. Influence of different textile fibers on characterization of dyeing wastewater and final effluent. Environ. Monit. Assess. 2018. [CrossRef] [PubMed]

2. Akhtar, M.F.; Ashraf, M.; Javeed, A.; Anjum, A.A.; Sharif, A.; Saleem, A.; Akhtar, B.; Khan, A.M.; Altaf, I. Toxicity appraisal of untreated dyeing industry wastewater based on chemical characterization and short term bioassays. Bull. Environ. Contam. Tox. 2016, 96, 502-507. [CrossRef] [PubMed] 
3. Liang, J.; Ning, X.A.; Kong, M.; Liu, D.; Wang, G.; Cai, H.; Sun, J.; Zhang, Y.; Lu, X.; Yuan, Y. Elimination and ecotoxicity evaluation of phthalic acid esters from textile-dyeing wastewater. Environ. Pollut. 2017, 231, 115-122. [CrossRef] [PubMed]

4. Kim, H.L.; Cho, J.B.; Park, Y.J.; Cho, I.H. Treatment and toxicity reduction of textile dyeing wastewater using the electrocoagulation-electroflotation process. J. Environ. Sci. Heal. A 2016, 51, 661-668. [CrossRef] [PubMed]

5. Chequer, F.M.; Lizier, T.M.; de Felicio, R.; Zanoni, M.V.; Debonsi, H.M.; Lopes, N.P.; de Oliveira, D.P. The azo dye Disperse Red 13 and its oxidation and reduction products showed mutagenic potential. Toxicol. In Vitro 2015, 29, 1906-1915. [CrossRef] [PubMed]

6. Maeda, C.H.; Araki, C.A.; Moretti, A.L.; de Barros, M.; Arroyo, P.A. Adsorption and desorption cycles of reactive blue BF-5G dye in a bone char fixed-bed column. Environ. Sci. Pollut. Res. 2018. [CrossRef] [PubMed]

7. Naushad, M.; ALOthman, Z.A.; Awual, M.R.; Alfadul, S.M.; Ahamad, T. Adsorption of rose Bengal dye from aqueous solution by amberlite Ira-938 resin: Kinetics, isotherms, and thermodynamic studies. Desalin. Water Treat. 2016, 57, 13527-13533. [CrossRef]

8. Sharma, G.; Naushad, M.; Kumar, A.; Rana, S.; Sharma, S.; Bhatnagar, A.; Stadler, F.J.; Ghfar, A.A.; Khan, M.R. Efficient removal of coomassie brilliant blue R-250 dye using starch/poly(alginic acid-cl-acrylamide) nanohydrogel. Process Saf. Environ. 2017, 109, 301-310. [CrossRef]

9. Khaled, A.; El Nemr, A.; El-Sikaily, A.; Abdelwahab, O. Removal of direct N Blue-106 from artificial textile dye effluent using activated carbon from orange peel: Adsorption isotherm and kinetic studies. J. Hazard. Mater. 2009, 165, 100-110. [CrossRef] [PubMed]

10. Suganya, S.; Senthil Kumar, P.; Saravanan, A.; Sundar Rajan, P.; Ravikumar, C. Computation of adsorption parameters for the removal of dye from wastewater by microwave assisted sawdust: Theoretical and experimental analysis. Environ. Toxicol. Pharmacol. 2017, 50, 45-57.

11. Khan, A.; Afzal, S.; Mustafa, H.; Qumreen, M. Data article for adsorption of chemically activated fullers earth and rice husk for removal of dri-marine reactive red dye. Data Brief 2018, 21, 189-200. [CrossRef] [PubMed]

12. Wu, J.; Zhang, T.; Chen, C.; Feng, L.; Su, X.; Zhou, L.; Chen, Y.; Xia, A.; Wang, X. Spent substrate of Ganodorma lucidum as a new bio-adsorbent for adsorption of three typical dyes. Bioresour. Technol. 2018, 266, 134-138. [CrossRef] [PubMed]

13. Xing, Z.; Zhao, X. Mushroom production in China: The illegal use of fluorescent whitening agents (FWAs) and related outbreaks. In Global Safety of Fresh Produce; Woodhead Publishing Limited: Sawston, Cambridge, UK, 2014; pp. 401-408.

14. Herrero-Hernandez, E.; Andrades, M.S.; Marin-Benito, J.M.; Sanchez-Martin, M.J.; Rodriguez-Cruz, M.S. Field-scale dissipation of tebuconazole in a vineyard soil amended with spent mushroom substrate and its potential environmental impact. Ecotox. Environ. Saf. 2011, 74, 1480-1488. [CrossRef] [PubMed]

15. Li, S.; Li, D.; Li, J.; Li, Y.; Li, G.; Zang, B.; Li, Y. Effect of spent mushroom substrate as a bulking agent on gaseous emissions and compost quality during pig manure composting. Environ. Sci. Pollut. Res. Int. 2018, 25, 12398-12406. [CrossRef] [PubMed]

16. Economou, C.N.; Diamantopoulou, P.A.; Philippoussis, A.N. Valorization of spent oyster mushroom substrate and laccase recovery through successive solid state cultivation of Pleurotus, Ganoderma, and Lentinula strains. Appl. Microbiol. Biot. 2017, 101, 5213-5222. [CrossRef] [PubMed]

17. Correa, R.C.; da Silva, B.P.; Castoldi, R.; Kato, C.G.; de Sa-Nakanishi, A.B.; Peralta, R.A.; de Souza, C.G.; Bracht, A.; Peralta, R.M. Spent mushroom substrate of Pleurotus pulmonarius: A source of easily hydrolyzable lignocellulose. Folia Microbiol. 2016, 61, 439-448. [CrossRef] [PubMed]

18. Tay, C.C.; Liew, H.H.; Redzwan, G.; Yong, S.K.; Surif, S.; Abdul-Talib, S. Pleurotus ostreatus spent mushroom compost as green biosorbent for nickel (II) biosorption. Water Sci. Technol. 2011, 64, 2425-2432. [CrossRef] [PubMed]

19. Jiang, Y.; Hao, R.; Yang, S. Equilibrium and kinetic studies on biosorption of $\mathrm{Pb}(\mathrm{II})$ by common edible macrofungi: A comparative study. Can. J. Microbiol. 2016, 62, 329-337. [CrossRef] [PubMed]

20. Sewu, D.D.; Boakye, P.; Jung, H.; Woo, S.H. Synergistic dye adsorption by biochar from co-pyrolysis of spent mushroom substrate and Saccharina japonica. Bioresour. Technol. 2017, 244, 1142-1149. [CrossRef] [PubMed] 
21. He, P.; Li, F.; Huang, L.; Xue, D.; Liu, W.; Xu, C. Chemical characterization and antioxidant activity of polysaccharide extract from spent mushroom substrate of Pleurotus eryngii. J. Taiwan Inst. Chem. E 2016, 69, 48-53. [CrossRef]

22. Islam, M.S.; McPhedran, K.N.; Messele, S.A.; Liu, Y.; Gamal El-Din, M. Isotherm and kinetic studies on adsorption of oil sands process-affected water organic compounds using granular activated carbon. Chemosphere 2018, 202, 716-725. [CrossRef] [PubMed]

23. AL-Othman, Z.A.; Ali, R.; Naushad, M. Hexavalent chromium removal from aqueous medium by activated carbon prepared from peanut shell: Adsorption kinetics, equilibrium and thermodynamic studies. Chem. Eng. J. 2012, 184, 238-247. [CrossRef]

24. Borsarelli, C.D.; Bertolotti, S.G.; Previtali, C.M. Thermodynamic changes in the photoinduced proton-transfer reaction of the triplet state of safranine-T. Photochem. Photobiol. Sci. 2002, 1, 574-580. [CrossRef] [PubMed]

25. Dhodapkar, R.; Rao, N.N.; Pande, S.P.; Nandy, T.; Devotta, S. Adsorption of cationic dyes on Jalshakti ${ }^{\circledR}$, super absorbent polymer and photocatalytic regeneration of the adsorbent. React. Funct. Polym. 2007, 67, 540-548. [CrossRef]

26. Alqadami, A.A.; Naushad, M.; Alothman, Z.A.; Ahamad, T. Adsorptive performance of MOF nanocomposite for methylene blue and malachite green dyes: Kinetics, isotherm and mechanism. J. Environ. Manag. 2018, 223, 29-36. [CrossRef] [PubMed]

27. Albadarin, A.B.; Collins, M.N.; Naushad, M.; Shirazian, S.; Walker, G.; Mangwandi, C. Activated lignin-chitosan extruded blends for efficient adsorption of methylene blue. Chem. Eng. J. 2017, 307, 264-272. [CrossRef]

28. Daneshvar, E.; Vazirzadeh, A.; Niazi, A.; Kousha, M.; Naushad, M.; Bhatnagar, A. Desorption of Methylene blue dye from brown macroalga: Effects of operating parameters, isotherm study and kinetic modeling. J. Clean. Prod. 2017, 152, 443-453. [CrossRef]

29. Naushad, M.; Ahamad, T.; Al-Maswari, B.M.; Alqadami, A.A.; Alshehri, S.M. Nickel ferrite bearing nitrogen-doped mesoporous carbon as efficient adsorbent for the removal of highly toxic metal ion from aqueous medium. Chem. Eng. J. 2017, 330, 1351-1360. [CrossRef]

30. Naushad, M. Surfactant assisted nano-composite cation exchanger: Development, characterization and applications for the removal of toxic Pb2+ from aqueous medium. Chem. Eng. J. 2014, 235, 100-108. [CrossRef] 